\title{
MEIOS DE INVALIDAR O ATO ADMINISTRATIVO NO BRASIL
}

\author{
MARCOS AFONSO BORGES *
}

SUMĀRIO: 1. Introdução. 2. Ato. 2.1 - Ato Jurídico. 2.2 - Ato Administrativo. 2.2.1 - Atributos do ato administrativo. 2.2.2 - Controle do ato administrativo. 2.2.2.1 - Controle do ato administrativo pela jurisdição. 3. Contencioso administrativo. 3.1 - Conceito. 3.2. Modalidades. 3.3 - O contencioso administrativo no Brasil. 3.3.1 - No Brasil Colônia. 3.3.2. No Brasil Império. 3.3.3 - No Brasil República. 3.3.3.1 - Em face da Emenda Constitucional no. 01, de 1969. 3.3.3.2 - Tendo em vista a Emenda Constitucional no. 07, de 1977. 4. Meios de invalidar o ato administrativo no Brasil. 5. Conclusão.

1. Desde tempos imemoriais, quando os povos passaram a se organizar e a se desenvolver, a preocupação de se evitar a concentração de todo o poder do Estado nas mãos de um só homem, ou em um só órgão, dominou os estudiosos e os teóricos de então, que já vislumbravam na divisão do mesmo, a essência e a garantia de um Estado igualitário (1).

No entanto, embora apregoada de há muito, a repartição das funções governamentais somente no Século XVIII, com Montesquieu (2), recebeu melhor sistematização, no sentido de que em todo Estado devem existir três poderes, interdependentes, o Legislativo, o Executivo e o Judiciário. Desde então esse dogma passou a constituir a substância do Estado Liberal (3).

\footnotetext{
* Professor Titular de Direito Processual Civil da Faculdade de Direito da Universidade Federal de Goiás.

Trabalho apresentado no XII Congresso Argentino de Direito Processual e II Encontro Panamericano de Direito Processual (Rosário, Argentina).
} 
Não há dúvida de que a maioria dos Paises adota esse sistema, - que visa a contenção do poder pelo poder, com o intuito de estabelecer a harmonia entre os mesmos (4), porém a importância desta ou daquela função recebe coloração variada, tendo em vista não somente a índole de cada povo, mas, e, sobretudo, pelas circunstâncias momentâneas a determinar, ora aqui, ora acolá, modificações substanciais.

Muito embora a função do Executivo seja administrar, a do Legislativo legislar e a do Judiciário aplicar a lei ao caso concreto levado à sua apreciação, a história está a nos demonstrar que a decantada harmonia entre as referidas funções raramente se verifica, havendo sempre a supremacia desta sobre aquela ou aquelas, e vice versa, prevalecendo, na maioria dos povos, a força maior exercida pelo Executivo a determinar a prevalência de sua vontade, quer usurpando as outras funções, quer exigindo o cumprimento pelas mesmas de seus desejos.

Se é certo que tal circunstância hoje se verifica.com grande freqüência, principalmente nos países latinoamericanos, asiáticos e africanos, não menos certo é também que as funções ditadas por Montesquieu se exercem e se materializam através da prática de atos.

2. Ato, do latim actus, de agere (levar, conduzir), "tem o sentido de indicar, de modo geral, toda ação resultante da manifestação da vontade ou promovida pela vontade da pessoa. É tudo o que acontece pela vontade de alguém" (5).

2.1. Quando a manifestação da vontade tiver por escopo produzik efeitos jurídicos, isto é, adquirir, modificar ou extinguir direitos, ela recebe a denominação de ato jurídico, que, por seu turno, tendo em vista o órgão do qual promana, pode ser legislativo, jurisdicional e administrativo (6).

$\mathrm{O}$ ato legislativo é a manifestação desse poder, no sentido de tornar obrigatória uma norma jurídica.

Denomina-se jurisdicional $\mathrm{o}$ ato, quando praticado em Juízo, tiver por escopo solucionar a lide, ou atender à pretensão de pessoas acerca de interesses particulares, não em conflito, mas que pela sua importância, estão sujeitos à manifestação jurisdicioanal.

2.2. Será administrativo quando o ato se originar da Administração Pública e objetivar a declaração de direitos ou a imposição de obrigações à própria Administração ou aos administrados.

2.2.1. No entender da doutrina, o ato administrativo possui, em geral, certos atributos que lhe dão caráter próprio e peculiar, 
a diferenciá-lo de outros atos jurídicos.

Assim é que, em primeiro lugar, ele surge com a presunção de legitimidade, no sentido de que, dado o princípio da legalidade da Administração, os seus efeitos, a sua execução não podem ficar condicionados ao alvedrio dos administrados, a questionarem a sua legitimidade. Tal condicionamento viria, como é óbvio, contrariar a segurança e a rapidez da atividade do Poder Público, tão necessários à consecução dos fins que Ihe são cominados.

Em segundo lugar, o ato administrativo é imperativo, pois o seu cumprimento é obrigatório, coercitivo se necessário, independentemente de se verificar sua validade ou não.

Finalmente, o terceiro atributo do ato administrativo consiste na sua auto-executoriedade, isto é, ele pode ser executado diretamente pela Administração, sem pressupor nenhuma ordem judicial (7).

Muito embora os atributos atrás apontados impregnem o ato administrativo, pode ocorrer, e com muita freqüência isso se verifica, que ele, apesar de perfeito, editado por órgão competente e de acordo com as prescrições legais, ofereça ao administrado dúvidas, incertezas capazes de levá-lo a pleitear medidas no sentido de impugná-lo, de fazer cessar os seus efeitos.

2.2.2. Se é verdade que a fiscalização do ato administrativo pode se dar tanto pela Administração, como pelo Legislativo, o que se verifica, no entanto, com maior freqüência, principalmente nos países de sistema presidencialista, é o controle exercido pelo Judiciário, mediante provocação por parte do administrado (8).

2.2.2.1. Este controle "é o exercido privativamente pelos órgãos do Poder Judiciário sobre os atos administrativos do Executivo, do Legislativo e do próprio Judiciário quando realiza atividade administrativa" (9).

Atualmente, dois são os sistemas de controle pelo Judiciário, um por intermédio da jurisdição comum ou única e outro da jurisdição especial ou dúplice.

O primeiro, alicerçado no princípio "una lex, una jurisdictio", caracteriza-se pela competência exclusiva dos tribunais comuns para instruir e decidir todos os pedidos inclusive os em que a administração é parte.

O segundo, é aquele em que também a administração tem funções judicantes e denomina-se contencioso administrativo.

3. Sem embargo das críticas formuladas, a expressão contencioso administrativo, a denominar esse tipo dúplice de jurisdição, 
surgiu na França, por ocasião da Revolução Francesa, e é hoje unanimemente aceita tanto pela doutrina como pela jurisprudência (10).

3.1. A noção do contencioso administrativo é correlata à de justiça administrativa, e pode ser conceituada como sendo “o sistema de jurisdição em que os litígios entre a administração e administrados são resolvidos não pelo Poder Judiciário, mas por tribunais especiais - os tribunais administrativos" (11).

3.2. A doutrina universal distingue duas modalidades de contencioso administrativo: a primeira, denominada de sistema absoluto, é aquela que abrange todos os litígios em que a Administração é parte.

A segunda caracteriza o sistema moderado, em que os atos administrativos, ditos de "império" (12) são submetidos a apreciação de órgãos da administração e os denominados atos de "gestão" (13) à justiça comum.

Este último sistema, por seu turno, se divide em duas correntes, a primeira que atribui a jurisdição especial aos próprios funcionários públicos, ou melhor da Administração, e que exercem outras funções, os denominados ativos; a segunda que propugna pela criação de tribunais administrativos, diferenciados, não integrantes do Poder Judiciário, com competência para dirimir as lides de natureza administrativa (14).

3.3. Deixando de lado o exame do contencioso administrativo em outras legislações (15), passemos agora a enfocar o assunto tendo em vista a legislação brasileira.

3.3.1. Quando do descobrimento, em 1500, o sistema vigorante em Portugal era o da monarquia absoluta, e, como não poderia deixar de ser, prevalecia o sistema de jurisdição única, visto que o monarca exercia todas as funções. Desta forma, no Brasil, desde então passou a vigorar a mesma orientação.

O sistema dúplice, ou de jurisdição especial, foi introduzido, segundo os estudiosos do direito administrativo, em 1741, por intermédio das leis de 22 de dezembro, inspiradas pelo Marques de Pombal, via das quais foram criados o Tesouro Real Erário e o Conselho da Fazenda, com o intuíto de cobrarem as dívidas ativas da Fazenda.

Muito embora se vislumbre nessas normas a criação do contencioso administrativo, o certo é que ele tinha características próprias, diferentes das existentes em certos países, pois não era de sua competência as causas em que a Fazenda fosse sujeito passivo. 
Desde então outros contenciosos foram criados, com a outorga a outros órgãos da Administração de funções jurisdicionais.

3.3.2. Com a Independência, em 1822, surgiu uma tendência no sentido de se eliminar o contencioso administrativo, tanto que o projeto de Constituição de 1823 , de forma clara, submetia à competência exclusiva do Judiciário todas as matérias, inclusive as de natureza fazendária (16).

Ocorre que o Imperador, D. Pedro I, antes mesmo do término do trabalho da Assembléia Constituinte, a dissolveu, e antes de editar uma Carta Magna, baixou em 13 de novembro de 1823, um decreto criando um Conselho de Estado, com o objetivo de elaborar um projeto de Constituição e de assessorar o Executivo em assuntos de maior importância.

Esse Conselho mantido pela Constituição de 1824, foi posteriormente dissolvido, em 12 de agosto de 1834, em virtude da reação contrária dos lịberais.

Com características de um verdadeiro contencioso administrativo, o referido Conselho foi novamente criado, em 23 de novembro de 1841, sob o Império de D. Pedro II, tendo permanecido até o advento da nova forma de governo (17).

3.3.3. Com a proclamação da República, em 1889, tratou o Governo Provisório, dados os ideais positivistas liberais então em voga, de abolir o contencioso administrativo, o que fez por intermédio do Decreto-Lei no. 848, de 11 de outubro de 1890.

A Constituição de 1891 manteve a orientação e em seu artigo 60 (18) estabeleceu a competência dos Juizes e Tribunais Federais para os deslindes das causas intentadas contra a União ou a Fazenda Nacional.

As Leis Maiores de 1934, 1937, 1945 e 1967 também seguiram a mesma orientação, muito embora a de 1937, surgida com - Estado Novo (ditadura de Getúlio Vargas), houvesse lançado "alguns tentáculos, como o da competência concedida à Câmara de Reajustamento Econômico relativamente a ajuste e remissão de dívidas de agricultores (Decreto-lei no. 1888, de 15 de dezembro de 1939)" (19).

3.3.4 - Pela Emenda Constitucional no. 1, de 17 de outubro de 1969, foram mantidos com a mesma redação, ou com redação diversa, vários dispositivos da Carta de 1967, bem como acrescentados outros, dentre os quais o artigo 111, que introduz a expressão contencioso administrativo, nos seguintes termos: 
“A lei poderá criar contencioso administrativo e atribuir-Ihe competência para o julgamento das causas mencionadas no artigo anterior".

Esse artigo anterior, o 110, dispõe:

"Os litígios decorrentes das relações de trabalho dos servidores com a União, inclusive as autarquias e as empresas públicas federais, qualquer que seja o seu regime jurídico, processar-se-ão e julgar-se-ão perante os juizes federais devendo ser interposto recurso, se couber, para o Tribunal Federal de Recursos" (20).

Com a entrada em vigor da mencionada Emenda no. 1, a seguinte dúvida passou a preocupar os estudiosos.

"Pretenderia, por ventura, a Emenda no. 1 em seu artigo 111, implantar, efetivamente, no Brasil, o contencioso administrativo, ou seja, um sistema especial de jurisdição para processar os litígios entre Administração e administrado? E se se implantasse esse sistema de jurisdição, nos estritos limites da possibilidade constitucional, isso configuraria o instituto do contencioso administrativo, como é entendido universalmente, com forma e técnica rigorosa do direito público? (21).

Pela leitura atenta das normas constitucionais, se percebe, de pronto, que a resposta é negativa, pelos seguintes motivos:

Primeiro, porque, na realidade, esse contencioso seria uma justiça trabalhista administrativa, pois sua competência estaria restrita às lides oriundas das relações de trabalho dos servidores (22) com a União, autarquias e emprêsas públicas, em primeiro grau, pois de suas decisões caberia recurso para o Tribunal Federal de Recursos, que é órgão de justiça dita comum.

Segundo, porque não abrangeria as relações entre os referidos órgãos e os funcionários públicos (23), sujeitos ao regime estatutário e não celitário (24).

Terceiro, porque o parágrafo $4^{\circ}$. do artigo 153 da Constituição estabelece "que a lei não poderá excluir da apreciação do Poder Judiciário qualquer lesão de direito individual".

3.3.5. Quando já estava arraigado na doutrina brasileira o entendimento da impossibilidade do contencioso administrativo, veio a lume a Emenda Constitucional no. 7, de 13 de abril de 1977, que, alterando vários dispositivos da Carta e a ela incorporando outros, trouxe novamente à baila o assunto. 
No que pertine especificamente à matéria em foco, além de dar nova redação aos artigos 111, 122 inciso II e 153, § 40., acrescentou os artigos 203 e 205 (25).

Para melhor análise do problema torna-se necessária a transcrição dos referidos dispositivos, com as redações dadas, respectivamente pelas Emendas Constitucionais 1 e 7:

\section{EMENDA No. 1}

"Art. 111. A lei poderá criar contencioso administrativo e atribuir-Ihe competência para o julgamento das causas mencionadas no artigo anterior".

\section{EMENDA NO. 7}

“Art. 111. A Lei poderá criar contencioso administrativo e atribuir-lhe competência para o julgamento das causas mencionadas no artigo anterior (art. 153, § 40.)".

\section{EMENDA NO. 1}

"Art. 122. Compete aos Tribunais Federais de Recursos:

II - julgar, em grau de recurso, as causas decididas pelos juizes federais.

Parágrafo único: A lei poderá estabelecer a competência originária dos Tribunais Federais de Recursos para a anulação de atos administrativos de natureza tributária".

\section{EMENDA NO. 7}

"Art. 122. Compete ao Tribunal Federal de Recursos: II - julgar, originariamente, nos termos da lei, o pedido de revisão das decisões proferidas pelos contenciosos administrativos (art. 204)". 
EMENDA NO. 1

“Art. 153. A Constituição assegura aos brasileiros e aos estrangeiros residentes no País a inviolabilidade dos direitos concernentes à vida, à liberdade, à segurança e à propriedade, nos termos seguintes:

$\S$ 40. A lei não poderá excluir da apreciação do Poder Judiciário qualquer lesão de direito individual".

\section{EMENDA NO. 7}

“Art. 153. A Constituição assegura aos brasileiros e aos estrangeiros residentes no País a inviolabilidade dos direitos concernentes à vida, à liberdade, à segurança e à propriedade, nos termos seguintes:

$\S 40$. A lei não poderá excluir da apreciação do Poder Judiciário qualquer lesão de direito individual. $O$ ingresso em Juízo poderá ser condicionado a que se exaurem previamente as vias administrativas, desde que não exigida garantia de instância, nem ultrapassado o prazo de cento e oitenta dias para a decisão sobre o pedido".

\section{EMENDA NO. 7}

“Art. 203. Poderão ser criados contenciosos administrativos federais e estaduais, sem poder jurisdicional, para a decisão de questões fiscais e previdenciárias, inclusive relativas a acidentes do trabalho (art. 153, § 40. $)^{\prime \prime}$.

“Art. 204. A lei poderá permitir que a parte vencida na instância administrativa (art. 11 e 203) requeira diretamente ao Tribunal competente a revisão da decisão nela proferida".

Cotejando as normas acima transcritas verifica-se o seguinte:

a) - permanece a possibilidade da criação de uma justiça trabalhista administrativa, não integrante do Poder Judiciário, com a competência para dirimir os conflitos de natureza traba- 
Ihista entre servidores e a União, autarquias e empresas públicas, com recurso para o Tribunal Federal de Recursos (art. 11, combinado com o art. 111 da C. F.).

b) - permite-se a constituição de contenciosos administrativos, melhor diríamos, colegiados administrativos, federais e estaduais, sem função judicante, para as questões fiscais, previdenciárias e acidentárias, entre administrados, União, Estados, autarquias e empresas públicas, sujeitos à apreciação direta do Poder Judiciário, esgotadas as vias administrativas, quando exigidas, em que o Tribunal Federal de Recursos e os Tribunais de Justiça, nos limites de suas competências, funcionam com competência originária, por intermédio de ação própria (art. 203, 204, combinados com o art. 153, §40. e 112, inciso II da C.F.).

Do exposto é de se constatar, salvo melhor juízo, que, na realidade, no Brasil não há um contencioso administrativo nos moldes preconizados pela doutrina internacional. $\mathrm{O}$ que existe é a possibilidade de criação de colegiados administrativos sem função judicante.

4 - Desta forma, o administrado quando pretender invalidar um ato administrativo terá que se socorrer do Poder Judiciário, mesmo nas hipóteses em que a lei exige a exaustão das vias administrativas (26), mediante ação (27), cujo pedido poderá variar, tendo em vista as peculiaridades de cada caso (28).

Para tanto, poderá utilizar o administrado das ações de conhecimento, de execução e cautelar (29).

Nas primeiras os pedidos mais comuns são:

a) - pedido de mandado de seguranla, para proteger direito liquido e certo, não amparado por "habeas corpus", sempre que, ilegalmente ou com abuso de poder, alguém sofrer violação ou houver justo receio de sofrê-la por parte de autoridade, seja de que categoria for e sejam quais forem as funções que exerça (30).

b) - o pedido popular, para pleitear a anulação ou declaração de nulidade de atos lesivos ao patrimônio da União, Distrito Federal, dos Estados, dos Municípios, das entidades autárquicas, de sociedade de economia mista, de sociedades mútuas de seguro nas quais a União represente os segurados ausentes, de empresas públicas, de serviços sociais autônomos, de instituições ou fundações para cuja criação ou custeio o tesouro público haja concorrido ou concorra com mais de cinquenta por cento do patrimônio ou da receita ânua, de empresas incorporadas ao patrimônio da União, do Distrito Federal, dos Estados e dos Municípios e de 
quaisquer pessoas jurídicas ou entidades subvencionadas pelos cofres públicos (31).

c) - pedido anulatório, objetivando a declaração da nulidade do ato administrativo (32).

d) - pedido de consignação em pagamento, para assegurar, via autoridade judiciária, o pagamento de quantia ou coisa devida (33).

e) - pedido possessório, com o intuíto de fazer cessar a turbação, esbulho ou ameaça à posse do postulante (34).

f) - pedido cominatório com o escopo de obrigar a administração a prestar fato ou a obster-se de ato, sob certa cominação (35).

Nas segundas (de execução), os pedidos poderão versar sobre o pagamento de quantia certa, coisa certa, e de obrigação de fazer e não fazer (36).

Nas terceiras, os pedidos de cautela indicados para o caso, como o arresto, o sequestro, a busca e apreensão e a produção antecipada de prova (37).

Com referência à matéria penal, o pedido mais utilizado é o de Habeas Corpus, com o intuito de defender o direito de locomoção do administrado (38).

5 - Isto, posto, conclui-se que:

10. - No Brasil, o contencioso administrativo, na realidade, somente vigorou no período da Colônia e do Império.

20. - A atual Constituição Federal, embora fale em contencioso administrativo, na realidade permite a criação de colegiados administrativos, sem função judicante.

30. - O Poder Judiciário é o órgão competente para dirimir as lides surgidas entre o administrato e a Administração. 


\section{NOTAS}

1. Na Grécia, Platão em seu Diálogo das Leis, já propugnava pelo estabelecimento de freios contra a autoridade, e Aristóteles em sua obra Política chegou a esboçar a tripartição do poder em: legislativo, executivo e administrativo.

2. O princípio está exposto na obra "De L'Esprit des Lois".

3. O primeiro país a adotar a doutrina de Montesquieu foram os Estados Unidos da América, através de sua incorporação na Constituição de Virginia em 1776, seguida pelas Constituições de Massachussetts, Maryland, New Hampshire e pela própria Constituição Federal de 1787.

4. Os norte americanos denominam esse sistema de "freios e contrapesos".

$\mathrm{Na}$ realidade, partindo do princípio de que o poder de soberania, do qual nenhum Estado abre mão, é substancialmente uno e indivisível, não podemos, em verdade, falar em separação de poderes, mas somente em separação de funções, exercidas por cada órgão (Legislativo, Executivo e Judiciário) dentro das esferas de suas atribuições. Assim, os atos do Estado se manifestam por intermédio dos órgãos acima indicados, ditos governamentais.

5. De Plácido e Silva, Vocabulário Jurídico, vol. I, pág. 181, Editora Forense, Rio, $1^{\text {a }}$. edição.

6. A doutrina estabelece, tendo em vista a função de cada órgão do Poder Público, um conceito material e formal dos atos dele emanados, "No sentido material, se diz que um ato é legislativo, administrativo ou jurisdicional quando, pela sua natureza peculiar, está contido no âmbito de alguma dessas funções. No sentido formal ou orgânico, o ato será classificado como legislativo, administrativo ou jurisdicional conforme o órgão de que emana seja o Poder Legislativo, o Poder Executivo ou o Poder Judiciário. É comum, porém, que os caracteres material e orgânico se juntem nos atos dos órgãos do Poder Público, de modo que estes se apresentem identificados no conteúdo e na forma" (Miguel Seabra Fagundes, 0 Controle dos Atos Administrativos pelo Poder Judiciário, pág. 32, Editora Forense, Rio, 1957).

7. Vide, sobre o assunto, dentre outros Hely Lopes Meirelles, Direito Administrativo Brasileiro, pág. 131 e segs., Editora Revista dos Tribunais, São Paulo, 1981 e José Cretela Júnior, Curso de Direito Administrativo, págs. 135 e segs., Editora Forense, Rio, 1a. edição e Do Ato Administrativo, págs. 59 e segs., José Bushatsk Editor, São Paulo, 1972.

8. "Controle é a faculdade de vigilância, orientação e correção que um Poder, órgão ou autoridade, exerce sobre a conduta funcional do outro.

Controle Administrativo é todo aquele que o Executivo e os órgãos da Administração dos demais poderes exercem sobre suas próprias atividades, visando mantê-las dentro da lei, segundo as necessidades do serviço e as exigências técnicas e econômicas de sua realização, pelo que é um controle de legalidade e de mérito.

Controle legislativo ou parlamentar é o exercido pelos órgãos legislativos (Congresso Nacional, Assembléia Legislativa, Câmara de Vereadores) ou por comissões parlamentares, sobre determinados atos do Executivo, na dupla linha da legalidade e da conveniência pública, pelo que se caracteriza um controle eminentemente político, indiferente aos direitos individuais dos administrados, mas objetivando os superiores interesses do Estado e da comunidade" (Hely Lopes Meirelles, obra citada, págs. $638,643,676$ e 677).

9. Hely Lopes Meirelles, obra citada, pág. 683.

10. O instituto foi inserido na Constituição Francesa de 1791, mas tem sua origem na Lei no. 16, de 24.08.1790, cujo artigo 13 prescrevia o seguintes: "As funções judiciais são distintas e permanecerão sempre separadas das funções administrativas. Não poderão os Juízes, sob pena de prevaricação, perturbar de qualquer modo as operações dos.corpos administrativos, nem citar diante de si os administradores por motivos das funções que esses exercem". 
Segundo o magistério de José Cretela Júnior, "a expressão contencioso administrativo é formada de dois termos, contencioso e administrativo que, segundo alguns, seriam termos inconciliáveis, repelindo-se. Segundo outros, "administrativo" significa referente à administração; logo não há "contradictio in terminis". A doutrina aceita a denominação contencioso administrativo, embora possa não concordar com sua felicidade ou infelicidade ao captar determinada realidade". O que se verifica, no entanto, é que a expressão está incorporada, para sempre, na terminologia do direito administrativo internacional (verbete Contencioso Administrativo I, Enciclopédia Saraiva do Direito, Vol. 19).

11. José Cretela Júnior, Contencioso Administrativo na Constituição, in Revista de Direito Público, vol. 19, pág. 41).

12. "Atos de império ou de autoridade são todos aqueles que a Administração pratica usando de sua supremacia sobre o administrado ou servidor e lie impõe obrigatório atendimento" (Hely Lopes Meirelles, obra citada, pág. 140). Ou, como ensina Mário Masagão, "seriam aqueles em que o Estado aparece como soberano, a se dirigir aos súditos para ordenar, ou proibir alguma coisa" (Curso de Direito Administrativo, pág. 169, Editora Max Limonad, São Paulo, 3a. edição).

13. "Atos de gestão são os que a Administração pratica sem usar de sua supremacia sobre os destinatários" (Hely Lopes Meirelles, obra citada, pág. 140). Ou, como quer Mário Masagão, "aqueles em que o Estado procede como particular, gerindo seu patrimônio, como fazem as pessoas de direito privado" (Obra citada, pág. 169).

14. Sobre o assunto de forma mais completa vide, dentre outros, José Cretela Júnior, Contencioso Administrativo na Constituição, in Revista de Direito Público, vol. 19; E Mário Masagão, obra citada, págs. 317 e segs.

15. Sobre o assunto vide, dentre outros, os autores e as obras citadas no número anterior (14).

16. “Art. 225. O Juízo e a execução, em matéria fazendária, seguirá a mesma regra que o juízo e a execução dos particulares, sem previlégio de fôro".

17. Vide sobre a matéria, dentre outros, Mário Masagão, obra citada, pág. 324 e segs. e Dalmo de Abreu Dallari, o Conselho de Estado e o Contencioso Administrativo no Brasil, in Revista de Direito Público, vol. 11, págs. 33 segs.

18. "Art. 60. Compete aos Juízes ou Tribunais Federais processar e julgar:

a) - as causas em que alguma das partes fundar a ação, ou defesa, em disposição. da Constituição Federal;

b) - todas as causas propostas contra o governo da União ou Fazenda Nacional, fundadas em dịsposições da Constituição, leis e regulamentos do Poder Executivo, ou em contratós celebrados com o mesmo governo.

19. Mário Masagão, obra citada, pág. 326.

20. Autarquia é o serviço autônomo criado por lei, com personalidade jurídica, patrimônio e receita próprios, para executar atividades típicas da Administração Pública, que requeiram, para seu melhor funcionamento, gestão administrativa e financeira descentralizada (art. 50., inciso I do Decreto-Lei no. 200, de 25.02. 1967.

Empresa Pública é a entidade dotada de personalidade jurídica de direito privado, com patrimônio próprio e capital exclusivo da União, criada por lei para a exploração de atividade econômica que o Governo seja levado a exercer por força de contingência e de conveniência administrativa, podendo revestir-se de qualquer das formas admitidas em direito (art. $5^{\circ}$, inciso II do Decreto-Lei no. 200, de 25.02.1967).

Esse artigo foi complementado pelo artigo $5^{\circ}$. do Decreto-Lei no 900 , de 29 de setembro de 1969, nos seguintes termos:

"Art. $5^{\circ}$.. Desde que a maioria do capital votante permaneça de propriedade da União, será admitida, no capital de Emprêsa Pública (art. 50 ., inciso II do Decreto-Lei no. 200, de 25.02.1967), a participação de outras pessoas jurídicas de direito público interno, bem como de entidades da Administração Indireta da União, 
dos Estados, Distrito Federal e Municípios.

Desta forma o capital não necessita de ser exclusivo da União, bastando que esta tenha a maioria votante.

21. José Cretela Júnoir, verbete citado da Enciclopédia Saraiva do Direito, vol. 19.

22. Servidor Público é toda pessoa que exerce uma atividade pública, de ordem material, técnica ou intelectual, qualquer que seja a natureza do vínculo com a administração.

23. Funcionário Público é um servidor público que se distingue dos demais porque é titular de "um cargo criado por lei, com denominação própria, em número certo e pago pelos cofres da entidade estatal em cuja estrutura se enquadra"' (Hely Lopes Meirelles, obra citada, pág. 380).

24. Regime estatutário é o disciplinado pelo Estatuto dos Funcionário público. Regime celitário é o disciplinado pela Consolidação das Leis do Trabalho, ao qual está submetido o servidor, que não funcionário público.

25. A Constituição Federal de 24 de janeiro de 1967, pela Emenda n ${ }^{\circ} .1$, de 17 de outubro de 1969 tinha 200 artigos. Pela Emenda no. 7, de 13 de abril de 1977 passou a ter 217 artigos.

26. A título de exemplo podemos invocar a Lei no. 1533 , de 31 de dezembro de 1951, disciplinadora do Mandado de Segurança e que exige, para a sua utilização, no artigo $5^{\circ}$,, inciso $\mathrm{I}$, a exaustão das vias administrativas.

$\mathrm{O}$ referido artigo e inciso, rezam o seguinte:

"Art. 50., Não se dará mandado de segurança quando se tratar:

I - de ato de que caiba recurso administrativo com efeito suspensivo independente de caução".

27. Ação é o direito público, subjetivo, abstrato, constitucional de solicitar a prestação juridicional, a Jurisdição.

28. Pedido é o direito material que o sujeito ativo pleiteia seja reconhecido e respeitado pelo sujeito passivo.

29. As ações de conhecimento objetivam uma decisão, uma sentença. As de execução, atos para obrigar o cumprimento de uma sanção sentencial, ou de uma obrigação consubstanciada em documento. As cautelares, medidas rápidas e provisórias para a garantia da eficácia da sentença a ser proferida no processo principal.

As ações de conhecimento subdividem-se em meramente declaratórias, condenatórias e constitutivas, conforme visarem uma decisão declarando a existência ou não de uma relação jurídica, ou a autenticidade ou falsidade de um documento, a imposição ao sujeito passivo de uma obrigação, passível de execução forçada, ou a criação modificação ou extinção de uma situação jurídica.

30. O Mandado de Segurança constitui uma garantia constitucional prevista no $\S 21$ do artigo 153 e disciplinada pela Lei no. 4.533 , de 31 de dezembro de 1951 . Reza o mencionado § 21 :

"Conceder-se-á mandado de segurança para proteger direito líquido e certo não amparado por habeas corpus, seja qual for a autoridade responsável pela ilegalidade ou abuso de poder".

31. A matéria é disciplinada pela Lei no 4.717 , de 27 de junho de 1965.

32. O pedido anulatório, formulado em ação de conhecimento, está previsto no artigo $4^{\circ}$. da Lei no. 5.869, de 11 de janeiro de 1973 (Código de Processo Civil).

33. A matéria está disciplinada no Código de Processo Civil, artigos 890 e seguintes (Lei no. 5.869, de 11 de janeiro de 1973).

34. Os artigos 920 e seguintes do Código de Processo Civil (Lei no. 5.869, de 11 de janeiro de 1973) cuidam desse pedido.

35. O pedido cominatório, no Código de Processo Civil de 1939, revogado, tinha procedimento especial de jurisdição contenciosa. A atual norma dinâmica brasileira não cuida especificamente do assunto, passando então a ser regulado pelas disposição do procedimento comum (artigos 271 e 287 do Código de Processo Civil, Lei no. 5.869, de 11 de janeiro de 1973).

36. Esta matéria constitui o Livro II do Código de Processo Civil (artigos 566 e se- 
guintes da Lei no. 5.869, de 11 de janeiro de 1973).

37. O Livro III do Estatuto Processual em vigor, artigos 796 e seguintes (Lei no. 5.869 , de 11 de janeiro de 1973), disciplina a matéria.

38. 0 \& 20 do artigo 153 da Constituinte Federal prescreve: "Dar-se-à habeas corpus sempre que alguém sofrer ou se achar ameaçado de sofrer violência ou coação em sua liberdade de locomoção, por ilegalidade ou abuso de poder. Nas transgressões disciplinares não cabe habeas corpus". O Código de Processo Penal (Decreto no. 3.689, de 3 de outubro de 1941) regula o assunto nos artigos 647 e seguintes. 